Utah State University

DigitalCommons@USU

\title{
On Some Aspects of Land Development When the Decision to Develop is Divisible
}

Amitrajeet A. Batabyal

Utah State University

Follow this and additional works at: https://digitalcommons.usu.edu/eri

\section{Recommended Citation}

Batabyal, Amitrajeet A., "On Some Aspects of Land Development When the Decision to Develop is Divisible" (1997). Economic Research Institute Study Papers. Paper 113.

https://digitalcommons.usu.edu/eri/113

This Article is brought to you for free and open access by the Economics and Finance at DigitalCommons@USU. It has been accepted for inclusion in Economic Research Institute Study Papers by an authorized administrator of DigitalCommons@USU. For more information, please contact digitalcommons@usu.edu.

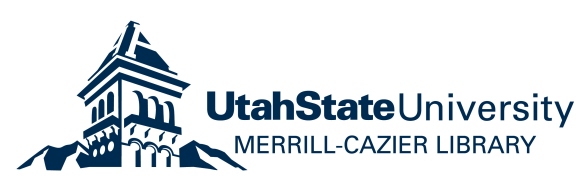


Econonomic Research Institute Study Paper

ERI \#97-02

\section{ON SOME ASPECTS OF LAND DEVELOPMEMT WHEN \\ THE DECISION TO DEVELOP IS DIVISIBLE}

by

AMITRAJEET A. BATABYAL

Department of Economics

Utah State University

Logan, UT 84322-3530

February 1997 


\title{
ON SOME ASPECTS OF LAND DEVELOPMENT WHEN \\ THE DECISION TO DEVELOP IS DIVISIBLE
}

\author{
Amitrajeet A. Batabyal, Assistant Professor \\ Department of Economics \\ Utah State University \\ Logan, UT 84322-3530
}

The analyses and views reported in this paper are those of the author. They are not necessarily endorsed by the Department of Economics or by Utah State University.

Utah State University is committed to the policy that all persons shall have equal access to its programs and employment without regard to race, color, creed, religion, national origin, sex, age, marital status, disability, public assistance status, veteran status, or sexual orientation.

Information on other titles in this series may be obtained from: Department of Economics, UMC 3530, Utah State University, Logan, Utah 84322-3530.

Copyright $\mathbb{C} 1997$ by Amitrajeet A. Batabyal. All rights reserved. Readers may make verbatim copies of this document for noncommercial purposes by any means, provided that this copyright notice appears on all such copies. 


\title{
ON SOME ASPECTS OF LAND DEVELOPMENT WHEN \\ THE DECISION TO DEVELOP IS DIVISIBLE
}

\begin{abstract}
The Arrow-Fisher-Henry (AFH) analysis of land development under uncertainty has been conducted in a two-period model in which the decision to develop is indivisible. Recently, this kind of analysis has been extended by Batabyal (1995, 1996a), Capozza and Helsley (1990), and Clarke and Reed (1990) to study the development question in a multiperiod framework. However, very little is known about the nature of the development decision when this decision is divisible. As such, in this paper I study the impact of divisibility on the land development decision over time and under uncertainty. In particular, I characterize the optimal decision rule governing the development of land and show how this rule depends on the stochastic aspects of the underlying problem.

JEL Classification: Q24, R14, D81
\end{abstract}

Key words: divisible, dynamic, land development, uncertainty 


\section{ON SOME ASPECTS OF LAND DEVELOPMENT WHEN \\ THE DECISION TO DEVELOP IS DIVISIBLE ${ }^{1}$}

\section{Introduction}

Resource and urban economists have been interested in the question of land development under uncertainty - with the development decision being potentially irreversible - at least since Weisbrod (1964) and Shoup (1970). Since then, Arrow and Fisher (1974) and Henry (1974) have shed considerable light on this development question. In particular, these researchers have identified a concept known as option value. The so-called Arrow-Fisher-Henry (AFH) concept of option value, also called quasioption value, tells us that when development is both indivisible and irreversible, a land developer, who ignores the possibility of obtaining new information about the consequences of such development, will invariably underestimate the benefits of preservation and hence skew the binary choice development decision in favor of development.

This simple and yet powerful result has been shown to hold in its most general form in a two-period setting. As such, one can ask whether the AFH result holds in more general settings in which the development decision (i) is being made in a multiperiod setting, and (ii) is divisible. With regard to the multiperiod nature of the development decision, Batabyal (1995, 1996a), Capozza and Helsley (1990), and Clarke and Reed (1990) have already shown that the prodevelopment bias described by AFH does carry over, but in a somewhat modified form.

Similarly, one can ask about the nature of the development decision when this decision can be varied continuously. Because the $\mathrm{AFH}$ analysis is conducted with linear benefit functions, the

\footnotetext{
${ }^{1}$ This research was supported by (i) the Utah Agricultural Experiment Station, Utah State University, Logan, UT 84322-4810, by way of project UTA 024, and by (ii) a Faculty Research Grant. Approved as journal paper No.
} 
optimal development policy involves developing land completely or not at all. When the relevant benefit functions are nonlinear, the possibility of partial development needs to be considered explicitly. This possibility and the related question of the nature of the optimal land development decision when this decision is divisible have received scant attention in the literature. In an early contribution, Epstein (1980) showed that unless the benefit function is intertemporally additive and concave in each of the decision variables, a divisible land development decision will not necessarily be prodevelopment. However, the strength of this conclusion is limited by the fact that Epstein's analysis is conducted in a three-period model. More recently, in an infinite horizon model, Clarke and Reed (1990) have also pointed to the possible optimality of partial development when the development decision is divisible. However, this Clarke and Reed result depends on their twin assumptions that the social valuation of services provided by (I) developed land, and (ii) wilderness follow Brownian motion processes.

Given the limited attention that has been accorded to this "divisibility" question in the literature, and given the rather specific nature of the extant findings about this question, the purpose of this paper is to apply the theory of gambling to study, in a fairly general setting, the impact of divisibility on the optimal land development decision. ${ }^{2}$ In particular, my principal aim will be to analyze the impact that the stochastic structure of the problem has on the optimal development decision, when this decision can be varied continuously.

The rest of this paper is organized as follows. Section 2 studies the impact of divisibility in a model with a relatively simple stochastic structure. In this model, the land developer's nonlinear

\footnotetext{
(1996b).

${ }^{2}$ For more on the theory of gambling, see Kelly (1956), Ross (1974, 1983), Subelman (1979a, 1979b), and Batabyal
} 
benefit from development function is assumed to be logarithmic. Section 3 analyzes a more general model of land development. Section 4 concludes and offers suggestions for future research.

\section{Divisible Land Development: The Logarithmic Case}

The models of this and the subsequent section are adapted from gambling models analyzed by Kelly (1956) and by Subelman (1979a, 1979b), and the spirit of my analysis is closely related to that in Batabyal (1996b). ${ }^{3}$ Consider a land developer who owns $l$ square units of land. When faced with a development opportunity, this developer must decide how much of these $l$ units he should develop. Like AFH, I shall assume that development is irreversible; unlike $\mathrm{AFH}$, I shall permit the development decision to be varied continuously. The developer solves his problem in a dynamic and stochastic framework. The framework is dynamic because the developer's decision depends on the availability of development opportunities; these opportunities arise sequentially over time. Further, the framework is stochastic because the decision as to what fraction of the $l$ units should be developed depends on the fixed probability $p$ that ex post, this development decision will be profitable. From this discussion, it is clear that with probability $q=(1-p)$ a decision to develop will be unprofitable.

The reader should note that the probabilities $(p, q)$ serve a dual purpose. First, they provide information as to whether a particular development decision will be profitable in a monetary sense. Second, indirectly these probabilities provide information about the develop/preserve dichotomy. For instance if $p$ is low, then an optimal course of action will call for more preservation at every development opportunity faced by the developer.

\footnotetext{
${ }^{3}$ Also see footnote 2 .
} 
Suppose that $t$ development opportunities present themselves sequentially. When faced with a particular opportunity to develop land, our developer must decide what fraction, $\beta \in[0,1]$, of his land to develop. In the rest of this paper, I shall measure the developer's profit from development in land units. Let $\delta \in(1, \infty)$ denote a profitability factor. This multiplicative factor $\delta$ measures the degree to which any particular decision to develop will be profitable. In other words, if a particular development decision is profitable, then our developer's profit (in terms of land) is $\delta \beta l$. Similarly, if this decision is unprofitable, then the developer's profit is $-\delta \beta l$.

Our developer's objective is to maximize the expectation of the logarithm of his final landholding. To this end, let $V_{t}(l)$ denote the maximum expected return to the developer when this developer's landholding is $l$, and $t$ further development opportunities will present themselves. Now, following the usual dynamic programming formulation, our developer's optimality equation is

$$
V_{t}(l)=\max _{\beta \in[0,1]}\left[p V_{t-1}(l+\delta \beta l)+q V_{t-1}(l-\delta \beta l)\right],
$$

with boundary condition $V_{0}(l)=\log (l)$. Using this boundary condition, I get

$$
V_{1}(l)=\max _{\beta \in[0,1]}[p \log (l+\delta \beta l)+q \log (l-\delta \beta l)] .
$$

Now, simplifying and then differentiating equation (2) with respect to $\beta$, we see that this equation is maximized by setting

$$
\beta^{*}=(p-q) / \delta \text {. }
$$

Substituting this value of $\beta$ from equation (3) into equation (2) gives

$$
V_{1}(l)=\log (l)+K
$$

where the constant $K=p \log (p)+q \log (q)+\log (2)$. Now using the optimality equation, i.e., equation (1), with $t=2$ gives

$$
V_{2}(l)=\max _{\beta \in[0,1]}[p \log (l+\delta \beta l)+q \log (l-\delta \beta l)+K] .
$$


Comparing equations (5) and (2), it is clear that equation (5) is maximized by setting $\beta$ equal to the value given in equation (3), i.e., $\beta^{*}=(p-q) / \delta$. Substituting this value of $\beta$ in equation (5) yields

$$
V_{2}(l)=\log (l)+2 K \text {. }
$$

Continuing the process which resulted in equations (4) and (6), we can see that $V_{t}(1)$-the developer's maximum expected return with landholding $l$ and with $t$ development opportunities outstanding-satisfies

$$
V_{t}(l)=\log (l)+t K
$$

and this equation is maximized in $\beta$ by setting $\beta^{*}=(p-q) / \delta$.

So far we have seen that when the developer's benefit function is logarithmic and when it is possible to vary the development decision continuously, it is optimal for our developer to develop the fraction $(p-q) / \delta$ of his land at every development opportunity. The optimal development policy given by equation (3) displays a number of interesting features. These are stated in Proposition 1: The optimal development policy $\beta^{*}=(p-q) / \delta$ tells us that (i) it is optimal to preserve all land if $p \leq 1 / 2$, (ii) for any positive level of development to occur $p>q$, (iii) a sufficient condition for all land to be developed is $p=\delta=1$, and (iv) $\beta^{*}$ is increasing in $p$ and decreasing in $\delta$.

Proof: (i) $\forall p \in[0,1 / 2]$, equation (3) yields a negative value for $\beta^{*}$. However, $\beta \in[0,1]$. Hence it is optimal to set $\beta^{*}=0$ for $p \leq 1 / 2$. (ii) $p>q \Leftrightarrow p>1 / 2 \Rightarrow \beta^{*}>0 \Rightarrow$ some positive level of development takes place. (iii) $p=\delta=1 \Rightarrow q=0 \Rightarrow \beta^{*}=1$. (iv) This follows upon inspection of equation (3).

Proposition 1 provides us with useful information about the developer's optimal policy. First, from part (I) we see that in this setting, the optimality of preservation is fundamentally linked to the likelihood that a given development opportunity will prove to be unprofitable. In particular, 
if $p \leq 1 / 2$, then it is optimal to preserve all land, all of the time. Second, from parts (ii) and (iv), we see that positive levels of development occur only when the underlying development opportunities are more likely than not to be profitable. Further, the extent of this development increases as the profitability probability rises. Finally, parts (iii) and (iv) tell us that when faced with a particular development opportunity, if this opportunity is profitable for sure and if the degree of profitability ( $\delta$ ) equals unity, then it is optimal to develop all land. Note that because the degree of profitability appears in the denominator of equation (3), ceteris paribus, as $\delta$ rises, the extent of development falls.

Thus far I have provided an explicit solution to our developer's problem. In order to do this, I exploited the fact that the logarithmic function is additive over successive amounts of land that are developed. In this connection, the reader should note that the use of any function with this additive property will permit one to obtain an explicit solution to the underlying land development problem. ${ }^{4}$ Without the use of a specific functional form, the analysis gets more complicated and only certain qualitative features of the optimal policy can be determined. To demonstrate this, I now eschew the use of a specific functional form and analyze a model of land development with a more general stochastic structure and an arbitrary benefit function.

\section{Divisible Land Development: The General Case}

The essential features of the current model and the notation remain as in the previous section. Now, the developer's benefit from development function is arbitrary and the stochastic structure of the problem is more involved. In particular, $p$, the probability that a decision to develop will prove

\footnotetext{
${ }^{4}$ In addition to the logarithmic function, the power function also exhibits this additive property.
} 
to be profitable ex post, is not fixed but is drawn at random from some distribution $G(\bullet)$, in advance of each of the $t$ possible development opportunities.

Suppose that our developer's objective is to maximize the expectation of a given function $b(\bullet)$ of his final land holding, where $b(\bullet)$ is the benefit function and this function is increasing in its argument. The state is represented by the pair $(l, p)$ where $l$ denotes the developer's landholding and $p$ denotes the profitability probability. With this specification of the objective and the state, I can now let $V_{t}(l, p)$ denote the maximum expected benefit to the developer when the state is $\left.\mathrm{I} l, p\right)$ and $t$ development opportunities are outstanding. Once again, following the usual dynamic programming formulation, the developer's optimality equation is

$$
V_{t}(l, p)=\max _{\beta \in[0, l]}\left[p \int_{0}^{1} V_{t-1}(l+\delta \beta, \epsilon) d G(\epsilon)+q \int_{0}^{1} V_{t-1}(l-\delta \beta, \epsilon) d G(\epsilon)\right],
$$

where $\epsilon$ is a random variable with distribution $G(\bullet)$, and the boundary condition is $V_{0}(l, p)=b(l)$. Note that the first argument of the $V_{t-1}(\bullet, \bullet)$ function is now altered to reflect the fact that the feasible set from which $\beta$ is chosen is $[0, l]$. Let $\beta_{t}^{*}(l, p)$ be the developer's optimal policy as a function of the state. In other words, $\beta_{t}^{*}(\bullet, \bullet)$ is that $\beta$ which maximizes equation (8). Unlike the previous section, in this case, a closed-form expression for $\beta_{t}^{*}(\bullet, \bullet)$, cannot be obtained. Nevertheless, one can still ask about the behavior of the optimal policy as a function of the two-state variables.

Here, the first question concerns the behavior of the optimal amount that is developed as a function of the developer's landholding $l$. While it might seem intuitive to conjecture that $\beta_{t}^{*}(\bullet, \bullet)$ is increasing or at least monotonic in $l$, Subelman (1979b) has already shown that both conjectures are false. From a practical perspective, this means that ceteris paribus, large landholdings do not automatically lead to policies that are prodevelopment (antipreservation). 
The second question concerns the behavior and, in particular, the monotonicity of $\beta_{t}^{*}(\bullet, \bullet)$ as a function of $p$, the probability that a particular development decision will be profitable. The answer to this question is contained in

Proposition 2: Because $b(\bullet)$ is increasing in its argument, it follows that for fixed $l$ and $t, \beta_{t}^{*}(\bullet, \bullet)$ is increasing in $p$.

Proof: I essentially have to show that $V_{f}(l, p)$ is supermodular. ${ }^{5}$ Now $b(\bullet)$ increasing implies that $V_{t-1}(l, \epsilon)$ is increasing in $l$, which implies that for all $\epsilon,\left\{V_{t-1}(l+\delta \beta, \epsilon)-V_{t-1}(l-\delta \beta, \epsilon)\right\}$ is increasing in $\beta$. This last result implies that

$$
\frac{\partial^{2}}{\partial \beta \partial p}\left[p \int_{0}^{1} V_{t-1}(l+\delta \beta, \epsilon) d G(\epsilon)+q \int_{0}^{1} V_{t-1}(l-\delta \beta, \epsilon) d G(\epsilon)\right] \geq 0
$$

holds. Equation (9) and Proposition 4.2 in Ross (1983, p. 6) together tell us that $V_{t}\left(l_{, p}\right)$ is supermodular. Hence $\beta_{t}^{*}(\bullet, \bullet)$ is increasing in $p$.

Proposition 2 tells us that all else being equal, as the profitability of development rises stochastically, our developer should preserve less and develop more of his land. Putting the results regarding the behavior of $\beta_{t}^{*}(\bullet, \bullet)$ in its two arguments together, we see that two opposite effects determine our developer's optimal policy. The first effect, the profitability effect says that, as the likelihood of a development decision being profitable rises, the developer should preserve less and develop more of his land. In turn, this increased profitability leads to greater landholdings because I am measuring profit in land units. Now, when faced with subsequent development opportunities, the second effect, i.e., the landholding effect, is ambiguous and hence offers no guidance to the developer. However, the profitability effect always says that with a higher $p$, more land should be

${ }^{5}$ For more on modularity, see Ross (1983) and Topkis (1978). 
developed. As a result, whether the intertemporal profile of land use will reflect a prodevelopment bias will depend on the properties of the developer's benefit function. More can be said about the nature and the extent of this potential bias, if one is willing, a la section 2 , to make assumptions about the form of the developer's benefit function.

\section{Conclusions}

In this paper I analyzed two models of land development in a dynamic and stochastic framework. In the first scenario, I characterized the land developer's optimal decision rule explicitly. This rule involved a probabilistic comparison of the desirability of development with the desirability of preservation. In the second scenario, I studied two qualitative features of the land developer's optimal decision rule. In both these scenarios, inter alia, I showed that it is optimal for a developer to develop (preserve) more land as the profitability probability $p$ increases (decreases).

The analysis of this paper can be extended in a number of directions. In what follows, I suggest two possible extensions. First, in a context similar to that of this paper, one could analyze the case in which, over time, the developer is able to influence the magnitude of the profitability probability. A study of this case will increase the practical import of the analysis of this paper. Second, empirical work which sheds light on the specifics of a developer's benefit function will enable one to better understand the development/preservation nexus in the context of land development decisions that are made over time and under uncertainty. 


\section{References}

Arrow, K.J., and A.C. Fisher. 1974. "Environmental Preservation, Uncertainty, and Irreversibility." Quarterly Journal of Economics 88:312-9.

Batabyal, A.A. 1995. "The Impact of Information on Land Development: A Dynamic and Stochastic Analysis." Economic Research Institute Study Paper \#95-13, Utah State University. Journal of Environmental Management (forthcoming).

Batabyal, A.A. 1996a. "The Timing of Land Development: An Invariance Result." American Journal of Agricultural Economics 78:1092-7.

Batabyal, A.A. 1996b. "Land Development and Preservation Over Time and Under Uncertainty: A Review and a Research Agenda." Mimeograph, Utah State University.

Capozza, D.R., and R.W. Helsley. 1990. "The Stochastic City." Journal of Urban Economics 28:187-203.

Clarke, H.R., and W.J. Reed. 1990. "Land Development and Wilderness Conservation Policies Under Uncertainty: A Synthesis." Natural Resource Modeling 4:11-37.

Epstein, L.G. 1980. "Decision Making and the Temporal Resolution of Uncertainty." International Economic Review 21:269-83.

Henry, C. 1974. "Option Values in the Economics of Irreplaceable Assets." Review of Economic Studies 41:89-104.

Kelly, J.L. 1956. "A New Interpretation of Information Rate." Bell System Technical Journal 35:917-26.

Ross, S.M. 1974. "Dynamic Programming and Gambling Models." Advances in Applied Probability 6:593-606.

Ross, S.M. 1983. Introduction to Stochastic Dynamic Programming. Academic Press: Orlando, FL.

Shoup, D.C. 1970. "The Optimal Timing of Urban Land Development." Regional Science Association Papers 25:33-44.

Subelman, E. 1979a. "The Dependence of Betting Strategies on the Probability of Winning." Journal of Applied Probability 16:855-66. 
1979b. "Optimal Betting Strategies for Favorable Games." Naval Research Logistics Quarterly 26:355-63.

Topkis, D.M. 1978. "Minimizing a Submodular Function on a Lattice." Operations Research 26:305-21.

Weisbrod, B.A. 1964. "Collective-Consumption Services of Individualized Consumption Goods." Quarterly Journal of Economics 78:471-7. 